\section{Mercury Pollution}

Environmental Mercury Contamination. Edited by Rolf Hartung and Bertram D. Dinman. Pp. ix +349 . (John Wiley: New York and London, September 1972.) $£ 9.40$.

THERE is increasing public awareness of the role of mercury in our environment. It is appropriate, therefore, that two leading health scientists, Dr Hartung and Dr Dinman, should undertake the task of editing a volume based on an International Conference on Environmental Mercury Contamination held in Ann Arbor, Michigan, in 1970. The result is an outstanding compilation and assessment of our present state of knowledge on mercury, an indication by the editors of what is still needed to be done, and an unemotional approach to the difficult question of mercury environmental threshold limit values. The data presented dispel immediate fear of dangerous mercury contamination in North America without permitting complacency.

The papers presented cover four main fields: the occurrence of mercury in the environment and in man, methods of mercury analysis, environmental dynamics of mercury and the biological effects of mercury compounds. Thus there is valuable information both for public health authorities and for research workers on the sources and subsequent distribution of mercury, the role of methylation processes and food chain phenomena, the effects of acute and chronic exposures of man and wildlife to both organic and inorganic mercury compounds, and from the chemist's standpoint, an assessment of present analytical methods. Bibliographies are provided with each paper and excellent summaries, comments and discussion papers have been supplied by the editors. It is to be regretted that some of the figures illustrating mercury geographical distributions are unreadable.

A large proportion of the work reported is concerned with mercury contamination in North America but there is a lesson to be learnt by all countries not yet concerned with pollution. The Japanese suffered the consequences of uncontrolled industrial mercury discharge and the subsequent Minamata and Niigata disasters are well documented in this book. Sweden quickly grasped the implications of high mercury fish values in food chains before severe biological effects developed in humans. Now the North American environment, particularly around the Great Lakes, has been studied in depth with the results reported at this conference. One of the principal difficulties facing all workers in this field concerns the environmental dynamics of mercury which are greatly complicated by the existence of several compounds of mercury, all of which have different biological properties. Furthermore, inter-conversions between compounds can occur, the most important of these being methylation of mercury in natural systems. This book will prove to be a most useful reference volume. It provides a wealth of information for all interested in trace elements in general and heavy metals in particular and their impact upon society and the environment.

WILliam TAYLOR

\section{The New Primatology}

The Functional and Evolutionary Biology of the Primates. Edited by Russell Tuttle. Pp. xxii +487 . (Aldine Atherton: Chicago and New York, April 1972.) \$15.

THIS volume of collected papers on various aspects of primatology provides further evidence of the tremendous importance of the Burg Wartenstein Symposia of the Wenner-Gren Foundation. These regular meetings of selected groups of specialists provide an excellent basis for the discussion and clarification of specific areas of research in physical anthropology, and the published papers are of immediate interest to many workers in the field. This particular volume covers a fairly large field, bringing in studies of fossil primates, cranial morphology, the central nervous system, post-cranial morphology and primate behaviour. Among the nineteen papers, there are several real gems - such as the succinct review of hominoid fossils (Simons and Pilbeam), the detailed survey of South African hominid material (Tobias), an extremely perceptive discussion of the "arboreal theory" of primate evolution (Cartmill), an explicit summary of long-term comparative studies of primate brains (Stephan), and an immaculate anatomical study of the morphology of the hominoid wrist (Lewis). There are also several theoretical papers analysing the scope for mathematical techniques (Oxnard; Cohen) and the application of special research techniques to the study of primate functional morphology (for example, Basmajian's paper on electromyography). Individually, many of these papers will prove to be indispensable for primatologists in various fields. The only criticism that might be made is that the range of the papers is too great, and that the aims of the Burg Wartenstein Symposia might have been more aptly met by concentration on just one of the several themes covered. The most obvious flaw in this respect is the inclusion of three papers on the behaviour of cercopithecoid monkeys, which bear little relationship to the other papers in the book although they are of interest in their own right. If the Wenner-Gren Symposia are to maintain their customary exceptionally high standard, it is essential that each Symposium should concentrate on a particular area of research, as was the case (for example) with old world monkeys.

One of the drawbacks with symposia which cover too wide a field is the automatic imbalance which emerges in the published papers. A very good example of this is provided by the dismissal of the "vertical-clinging-and-leaping concept" in the papers written by Szalay and Cartmill. Both authors have completely misinterpreted the original subject-matter in the same way, maintaining that Napier and Walker postulated vertical-clinging and leaping as the ancestral primate pattern of locomotion. What Napier and Walker in fact said was that vertical-clinging and leaping should possibly be regarded "as the earliest locomotor specialization of primates". In view of the fact that this volume is intended as a discussion of primate functional biology, it is a pity that a concept as important as this should not have been adequately discussed. Szalay and Cartmill have-so to speak-eaten the embryo along with the extra-embryonic membranes.

There is also some degree of imbalance in the discussion of the evolution of the primate nervous system. Despite his generally meticulous approach, Stephan really does seem to believe that the "basal insectivores" exhibit brains relatively identical in size and gross structure to those of Cretaceous ancestral mammals, and that various primates have been arrested at different stages in the evolutionary elaboration of the brain: "The graph based on the indices of neo-cortical progression shows that within the Primates many different evolutionary stages are preserved in extant species." Although this over-simplification is to some extent offset by Radinsky's neat account of primate endocasts (which actually illustrate gross brain structure at various points in the fossil record), even Radinsky accepts the widespread (but unproven) notion that there has been a reduction of olfactory areas throughout primate evolution. It is true that primates generally have relatively smaller olfactory areas than extant "basal insectivores"; but it has yet to be shown that any extant primate species has absolutely smaller olfactory areas than would have been found in an actual Cretaceous mammal of the same body size. It is only in terms of the latter comparison that "reduction of the palaeocortex and bulbus olfactorius" can have any real meaning. Again, this topic deserves adequate treatment. 